https://doi.org/10.14211/regepe.v7i2.707

\title{
"MEU PAI AINDA ESTÁ AQUI, NAS PESSOAS": SENTIDOS SUBJETIVOS NAS RELAÇÕES DE TRABALHO EM UMA EMPRESA FAMILIAR
}

Recebido: 23/08/2017

Aprovado: 25/01/2018

\author{
1 Lília Paula Andrade \\ 2 Mônica Carvalho Alves Cappelle \\ ${ }^{3}$ Rafaella Cristina Campos \\ ${ }^{4}$ Mozar José de Brito
}

\section{RESUMO}

Este estudo tem como objetivo compreender os sentidos subjetivos relacionados ao trabalho na perspectiva dos trabalhadores de uma empresa familiar. Para tanto, utilizou-se a epistemologia qualitativa de Fernando Luis González Rey como abordagem teórico-epistemológica. Quatro entrevistas foram realizadas com os trabalhadores dessa empresa. Os resultados confirmaram a existência de: i) sentidos subjetivos influenciados pela história de vida do fundador da empresa; ii) sentido subjetivo de trabalho como extensão da vida do fundador; iii) sentimento de pertencimento à organização; e iv) ligação estabelecida entre os próprios trabalhadores da empresa. A pesquisa realizada contribui para o entendimento dos pressupostos teóricos dos sentidos subjetivos no trabalho e ajuda na compreensão da lógica de gestão em empresas familiares. $O$ caso evidencia que a subjetividade desenvolve-se em meio a práticas sociais. Dessa maneira, os sentidos subjetivos no trabalho recebem influências de um contexto sócio-histórico e de questões conscientes e inconscientes.

Palavras-chave: Empresa Familiar; Subjetividade; Relações de Trabalho.

\footnotetext{
${ }^{1}$ Mestra em Administração pela Universidade Federal de Lavras- UFLA, Minas Gerais, (Brasil). E-mail: liliapaulandrade@yahoo.com.br ORCID ID: https://orcid.org/0000-0001-7214-2057

2 Doutora em Administração pela Universidade Federal de Minas Gerais - UFMG, Minas Gerais, (Brasil). E-mail: edmo@dae.ufla.br ORCID ID: https://orcid.org/0000-0002-0095-3405

${ }^{3}$ Mestra em Administração pela Universidade Federal de Lavras- UFLA, Minas Gerais, (Brasil). E-mail: rafaella_ccampos@hotmail.com ORCID ID: https://orcid.org/0000-0002-9478-0620

${ }^{4}$ Doutor em Administração pela Universidade de São Paulo - USP, São Paulo, (Brasil). E-mail: mozarbrito@dae.ufla.br ORCID ID: https://orcid.org/0000-0001-9891-9688
} 


\title{
"MY FATHER IS STILL HERE, IN THE PEOPLE": SUBJECTIVE SENSES IN WORK RELATIONSHIPS IN A FAMILY BUSINESS
}

\begin{abstract}
This study aims to understand the subjective senses related to work from the perspective of the employees of a family business. It was used a qualitative epistemology developed by Fernando Luis González Rey as a theoreticalepistemological approach. Four interviews were conducted with the workers who were selected to represent the functional areas of the business. The results supported the existence of: i) subjective senses influenced by the story of the business founder's life; ii) subjective feeling of work as an extension of the founder's life; iii) feeling of belonging to the business; and iv) a stablished link between the own businesses workers. The case of the family business demonstrates that the subjectivity in the work develops in the middle of social practices. In this way, the subjective senses at work are influenced by a socio-historical context and by conscious and unconscious questions.
\end{abstract}

Keywords: Family Business; Subjectivity; Work Relationships. 


\section{INTRODUÇÃO}

Todo trabalho possui um sentido para aquele que o pratica. $O$ trabalho é parte essencial da vida do ser humano, por meio dele o indivíduo se transforma e é capaz de transformar o meio em que vive (Antunes, 2005). O sentido subjetivo do trabalho é influenciado diretamente tanto por questões individuais conscientes e inconscientes, como também por relações e imposições coletivas, advindas do meio social onde se desenvolvem os indivíduos (González Rey, 2003). Dentre os vários tipos organizacionais, a familiar possui especificidades próprias capazes de influenciar o indivíduo (Aygören, \& Nordqvist, 2015) e seus sentidos subjetivos no trabalho (Davel, \& Colbari, 2000).

O trabalho é uma das condições básicas e foi por meio dele que a espécie humana desenvolveu-se e perpetuou-se. Pelo trabalho, o homem coloca em movimento suas forças físicas e torna-se útil à sua própria vida (Antunes, 2005). Para Max Weber, o trabalho é a condição da dignidade e moralidade humana (Muller, 2005). Já a palavra "sentido" vem do latim (sensus) (Tolfo, \& Piccinini, 2007) e significa perceber, sentir, saber para encontrar o caminho ou ir mentalmente (Harper, 2017). Tal definição, atrelada ao conceito de trabalho, pode se referir a comportamentos, construtos e ainda a uma base psicológica e sociológica que permeia o indivíduo. Já por subjetividade entende-se que é composta por ações, práticas sociais e pensamentos conscientes e inconscientes (González Rey, 2003). Portanto, também permeia e é permeada pelas relações de trabalho.

Tem sido crescente a quantidade de estudos que buscam compreender o sentido e o significado do trabalho como, por exemplo: Bauman (1998), Tolfo e Piccinini (2007), Junqueira, Medeiros, Schwingel, Carreno, Saldanha e Jungles (2011), Bendassolli, Coelho-Lima, Pinheiro e Siqueira Gê (2015), Schweitzer, Gonçalves, Tolfo e Silva (2016) e Schmidt, Barbosa, Pinceli e Lucca (2017). Porém, poucos foram identificados em empresas familiares, assim como as pesquisas feitas por Garcia e Moreira (2008).

Portanto, para compreender tais aspectos relacionados ao sentido do trabalho, buscou-se responder à seguinte questão: quais sentidos subjetivos relacionados ao trabalho podem ser percebidos em uma empresa familiar? O objetivo desta pesquisa consiste em compreender os sentidos subjetivos relacionados ao trabalho na perspectiva dos trabalhadores de uma empresa familiar.

Revista de Empreendedorismo e Gestão de Pequenas Empresas | v.7 | n.2 | p. 145-169 | Mai/Ago. 2018. 
Como orientação teórico-metodológica, foi utilizada a epistemologia qualitativa de González Rey (2003; 2005).

Quanto à escolha do local de pesquisa, este é considerado relevante, pois ao longo da história do país, as organizações familiares têm contribuído de modo significativo para a economia nacional (Gonçalves, 2000; Souza, Maranhão, Leone, \& Oliveira, 2017). Essa mesma importância acontece não apenas no Brasil, mas também em diversos países ao redor do mundo (Belmonte, \& Freitas, 2013).

Além disso, pode-se afirmar que os aspectos subjetivos da família interferem de maneira expressiva na lógica das relações de trabalho (Lopes, Carrieri, \& Saraiva, 2013; Aygören, \& Nordqvist, 2015). Apesar disso, ainda são poucos os trabalhos voltados à compreensão dos aspectos psicológicos nessa tipologia organizacional (Souza et al., 2017).

A família é o princípio moralizador e de controle social que tem auxiliado na perpetuação da "ética do trabalho", que foi e é base para a sustentação da sociedade industrial (Davel, \& Colbari, 2000; Berger, \& Luckmann, 2004). Ela é a responsável pela socialização primária de um indivíduo e é por meio dela que o sujeito interioriza a realidade e percebe os eventos como significativos (Berger, \& Luckmann, 2004). A subjetividade nas organizações familiares é marcada por laços afetivos que vêm de ligações estabelecidas antes dos negócios e que se constitui em "manifestações subjetivas de poder e de controle" que são apresentadas de maneira única (Lopes et al., 2013, p. 226).

Uma das forças da organização familiar é a questão cultural que frequentemente está atrelada ao seu fundador (Davel, \& Colbari, 2000). Neste ambiente, a cultura familiar mistura-se com a cultura da empresa e compartilha dos mesmos valores e comportamentos (Gonçalves, 2000; Souza et al., 2017). Esse contexto cultural está diretamente relacionado com a estabilidade e o sucesso dessas organizações (Frezatti, Bido, Mucci, \& Beck, 2017), fato que justifica a relevância desta pesquisa.

Este artigo apresenta cinco seções. Além desta introdução, é feita uma apresentação sobre sentidos subjetivos sob a ótica de González Rey, na sequência, apresentam-se os procedimentos metodológicos, na quarta seção são discutidos os resultados e, por fim, tecidas as considerações finais. 


\section{REFERENCIAL TEÓRICO}

Este referencial se divide em duas seções. A primeira trata da apresentação da teoria da subjetividade e dos sentidos subjetivos pela perspectiva de Gonzalez Rey. Já na segunda seção, são discutidos estudos que contribuem para a compreensão dos sentidos subjetivos em organizações familiares.

\subsection{Subjetividade e Sentidos Subjetivos pela Perspectiva de González Rey}

A teoria da subjetividade de González Rey surge da necessidade de se pensar a psicologia de uma maneira diferente da perspectiva dominante que possui características reducionistas, quantitativas e mecanicistas (Silva, 2013). Esta teoria contribuiu para se pensar a psicologia sob um prisma mais subjetivo (González Rey, 2003). Os estudos em psicologia não consideravam que a psicologia individual e a psicologia social deveriam ser analisadas conjuntamente, haja vista que ambas estão presentes na subjetividade dos indivíduos (González Rey, 2003; 2005; 2007).

As palavras "sentido" e "significado" têm tido uma ampla utilização na literatura psicológica (González Rey, 2007). De acordo com este mesmo trabalho, a categoria "sentido" foi introduzida por Vygotsky (1968), mas ignorada pela psicologia soviética até os anos oitenta e substituída pela categoria de sentido pessoal de Leontiev (1978). Na psicologia ocidental, essa categoria apareceu influenciada por Vygotsky (1968), por autores da psicologia norte americana e outros que se preocuparam com a ação. González Rey propôs sua definição de "sentido subjetivo" e foi influenciado pelas contribuições e críticas a esses autores. Por esse motivo, é importante ressaltar algumas delas.

Vygotsky (1968; 1987) se preocupou com a complexidade existente na palavra sentido, que para ele envolvia uma conexão entre pensamento, palavra e linguagem e sua relação com a consciência como sistema ou como o todo (psiquê). Ele compreendeu que o sentido está além da palavra e que inclui também os afetos e as emoções. Para o referido autor, a relação entre cognitivo e afetivo são partes essenciais da categoria "sentido". Apesar disso, González Rey (2007) afirma que Vygotsky foi criticado por não desenvolver de maneira congruente desde o início de sua obra essa relação. 
Leontiev (1992) acrescenta que, além de se considerar o cognitivo e o afetivo em unidade, é preciso considerá-los como um sistema dinâmico que relaciona a dinâmica do pensamento com a dinâmica do comportamento e a atividade da personalidade. A psicologia ocidental e soviética desenvolveu-se sob a mesma dificuldade para compreender o caráter subjetivo da categoria "sentido" e, sobretudo, houve uma necessidade de discussão sobre o tema da subjetividade em uma perspectiva histórico-cultural (González Rey, 2007).

Apesar das críticas, as contribuições de Vygotsky (1968; 1987) ajudaram na compreensão de que o sentido é capaz de se articular no funcionamento psíquico do sujeito. Essas contribuições foram importantes, sobretudo, para a compreensão das reflexões dos sujeitos para o estudo dos sentidos subjetivos e para 0 desenvolvimento da Teoria da Subjetividade (González Rey, 2003; 2007).

González Rey (2007) afastou-se de qualquer associação estática entre conteúdo psicológico e comportamento, mas considerou a existência de suas relações múltiplas. Com a Teoria da Subjetividade, González Rey vai além do proposto por Vygotsky (1968; 1987), ao estabelecer uma relação entre o afetivo e o intelectual. González propõe uma relação entre o simbólico e o emocional, entre o sentido subjetivo e a subjetividade como um sistema.

A primeira definição de sentido subjetivo feita por González Rey aconteceu em 2000, quando destacou a existência de uma multiplicidade de registros objetivos que afetavam o homem em sua integridade vital e subjetiva (González Rey, 2003; 2007). Desde então, o autor compreende o sentido subjetivo não apenas reduzido ao conceito de subjetividade individual, mas também atrelado ao conceito de subjetividade social. Considera que os sentidos subjetivos são produzidos em diferentes esferas da sociedade.

González Rey (2003; 2005; 2007), portanto, percebeu a importância das práticas sociais, ao mesmo tempo, não negou a psiquê como definição ontológica, mas compreendeu que o sentido subjetivo e a organização subjetiva dos sistemas humanos se inter-relacionam nas ações dos indivíduos.

A subjetividade sob tal perspectiva é indissociável dos contextos sociais e culturais onde acontecem as ações humanas (González Rey, 2003; 2007). Ela não acontece apenas de acordo com as predisposições da mente humana, mas possui relações com a dimensão social e cultural "e, portanto, não é um tema apenas da psicologia, mas das ciências sociais em geral” (Gonzaléz Rey, 2007, p. 173). De 
acordo com este autor, o sentido subjetivo pode ser caracterizado como a multiplicidade de elementos presentes na subjetividade social organizados em uma dimensão simbólica e emocional, que possibilita ao homem desenvolver-se em todos os seus aspectos.

Essa compreensão é importante, pois permite compreender a sociedade a parti de uma nova dimensão, que considera a ação individual e suas consequências sobre o homem e sobre os diferentes espaços da vida social (González Rey, 2003; 2007). Em outras palavras, essa teoria considera que a subjetividade se desenvolve em um contexto sócio-histórico e é influenciada por questões de ordem consciente e inconsciente, é socialmente construída e historicamente situada. O sujeito, portanto, deve ser compreendido em sua complexidade de práticas sociais (González Rey, 2003; 2005; 2007; Silveira, \& Palassi, 2011).

Essa noção implica ainda a compreensão de que os comportamentos produzidos em determinados cenários são produtos dos sentidos subjetivos desse comportamento, que se relacionam com as experiências e situações anteriores já vividas pelo indivíduo (González Rey, 2003; 2007; Silva, 2013). O sentido subjetivo, portanto, é percebido como inseparável da subjetividade e, sobretudo, como inseparável dos processos simbólicos e das emoções (González Rey, 2003; 2007; Silva, 2013).

Para González Rey (2003), a subjetividade é mais do que "algo que vem de fora e passa a estar dentro" do indivíduo (Silva, 2013 p. 25), ela não acontece apenas no nível individual, mas também envolve o coletivo e as estruturas em que se encontram os sujeitos. Nesse sentido, a cultura, a subjetividade e o sujeito estão em relação e devem ser considerados em constante processo de recursividade (González Rey, 2003; Silva, 2013).

Silva e Cappelle (2013) aplicaram os conceitos propostos por González Rey e mostraram, por meio de pesquisa realizada com prostitutas, como o prazer, a emoção e a subjetividade humana têm sido interpretados nesse tipo de trabalho. As autoras evidenciaram sentidos subjetivos influenciados por relações dos indivíduos com a família, com a percepção de múltiplas necessidades materiais e imateriais, e até mesmo uma relação de trabalho confundida com a própria vida das prostitutas.

Silveira e Palassi (2011) realizaram um estudo de caso na Secretaria do Estado da Fazenda do Espírito Santo (Sefaz), em que foram entrevistados sete servidores públicos com o objetivo de compreender-se os sentidos subjetivos ante à 
participação no trabalho. Foi evidenciada a existência de diversos sentidos subjetivos como a falta de reconhecimento do trabalho no serviço público, o excesso de burocracia que influencia a satisfação no trabalho e a dedicação ao trabalho do servidor que, por vezes, influencia negativamente a relação com sua vida familiar.

Tacca e González Rey (2008) utilizaram a teoria da subjetividade para compreenderem as singularidades dos alunos no processo de aprendizado. Os autores perceberam que os sentidos subjetivos de aprendizagem são produzidos ao longo da trajetória histórica de cada aluno, bem como de suas situações de vida e espaços compartilhados.

A aplicação da Teoria da Subjetividade permite a produção de conhecimentos que dificilmente podem ser acessíveis por métodos e teorias tradicionais. Apesar disso, existem algumas dificuldades que devem ser consideradas pelos pesquisadores que desejam compreender os sentidos subjetivos por tal perspectiva. São elas: 1) a compreensão teórico-metodológica de González Rey $(2003 ; 2005)$ se afasta completamente dos raciocínios objetivistas que por vezes são requeridos nas pesquisas qualitativas; 2) exige-se que o pesquisador tenha muito "cuidado ao lidar com os sujeitos da pesquisa", "a fim de não perder a confiança do grupo investigado"; e 3) "as interpretações de cada momento empírico" não são realizadas de maneira sequencial, os dados passados são constantemente reinterpretados e confrontados com dados presentes (Silveira, \& Palassi, 2011, p. 217).

Para compreender a subjetividade e as relações de trabalho em empresas familiares, será apresentada a subjetividade e sentidos subjetivos em empresas familiares na próxima seção.

\subsection{Subjetividade e Sentidos Subjetivos em Empresas Familiares}

Os estudos sob a perspectiva familiar têm crescido (Short, Sharma, Lumpkin, \& Pearson, 2016; Frezatti et al., 2017) e, além da sua importância socioeconômica, essas organizações possuem especificidades que têm instigado os pesquisadores, sobretudo, sobre abordagens sociológicas, antropológicas e simbólicas (Frezatti et al., 2017; Lescura, Brito, Borges, \& Capelle, 2012).

Gonçalves (2000, p. 8) define como organização ou empresa familiar aquela que apresenta as seguintes características: a) a empresa é propriedade de uma 
família; b) a gestão da empresa pertence à família; e c) a "família é responsável pela administração do empreendimento, com participação de um ou mais membros". Davel e Colbari (2000) explicam que a família é princípio emocional e afetivo que, ao contrário do mercado que é instável, promove segurança, afeto e respeito aos indivíduos.

Organizações familiares são percebidas como uma extensão da vida familiar dos sujeitos que a integram (Lopes, \& Carrieri, 2010; Carrieri, \& Lopes, 2012; Lopes, et al., 2013). A dinâmica organizacional dessas empresas deve ser percebida como indissociável das particularidades da família, lugar onde os aspectos subjetivos e psicológicos interferem na lógica das relações de trabalho (Lopes, \& Carrieri, 2010). Nas organizações familiares, os papéis profissional, racional, familiar e objetivo são cheios de afetividade oriundos das histórias de vida lá desenvolvidas. Portanto, não existe separação entre gestão organizacional e dinâmica de organização familiar (Carrieri, \& Lopes, 2012; Lopes, \& Carrieri, 2010; Lopes et al., 2013). O vínculo dos indivíduos dessas organizações é diferente do vínculo estabelecido em outros tipos organizacionais. Esse vínculo integra a subjetividade dos indivíduos (Aygören, \& Nordqvist, 2015; Lopes et al., 2013)

O indivíduo identifica-se com uma organização por meio de seus sentimentos, de respeito com o trabalho, sentimento de família, entre outros que permitem o sentimento de prazer (Lopes et al., 2013). Por esse motivo, a história de uma organização influencia de modo direto na subjetividade dos indivíduos que lá estão presentes, assim como foi evidenciado no estudo realizado por Carrieri e Lopes (2012), ao analisarem as histórias de vida que se desenvolveram em meio à relação família e organização.

As relações de trabalho precisam ser analisadas em sua situação objetiva e na subjetividade inerente às histórias de vida dos sujeitos que nela trabalham. "O trabalho pode ser palco de repetições vinculadas a vivências passadas, relacionadas a uma cadeia de significações pessoais, estando muitas vezes no campo do inconsciente" (Lopes, \& Carrieri, 2010, p. 481). O referencial simbólico e ideológico da família tem sido muito importante para a sedimentação de uma moral do trabalho e na construção de identidades empresariais e profissionais (Davel, \& Colbari, 2000; Lescura et al., 2012).

Garcia e Moreira (2008) utilizaram a epistemologia qualitativa de González Rey para compreenderem as relações de trabalho em uma empresa familiar 
fabricante de caixas d'águas em fibra de vidro e polietileno. Eles analisaram como sentido subjetivo o "mito de grande família" que promovia um papel de controle psicossocial dos vínculos. Lourenço e Ferreira (2012), ao realizarem uma pesquisa em uma organização familiar, também compreenderam a existência de um "mito do fundador", que orientava todas as relações de trabalho lá estabelecidas. Por trás da figura do fundador foram observadas relações de dominação, exploração e repressão do sujeito no ambiente de trabalho. Essas características são comuns nas relações de trabalho em organizações familiares e são silenciadas pelo discurso de família e pelo estabelecimento de vínculos afetivos (Lopes, \& Carrieri, 2010; Carrieri, \& Lopes, 2012; Lopes et al., 2013).

Todas estas especificidades próprias das organizações familiares serão apresentadas e aplicadas ao caso investigado. Na seção seguinte, é possível compreender como os resultados desta pesquisa foram obtidos e interpretados.

\section{PROCEDIMENTOS METODOLÓGICOS}

A pesquisa qualitativa se baseia na epistemologia qualitativa de González Rey (2005). Para esse autor, a aplicação dessa epistemologia exige que o pesquisador compreenda que o indivíduo é constituído a partir de sua reflexividade durante sua história de vida. Assim, durante todo esse processo, a emoção influencia no seu pensamento e modo de agir. Além disso, a teoria orientada por essa epistemologia busca a compreensão da pesquisa como um processo de comunicação e de diálogo, uma vez que o homem comunica-se nos diversos espaços sociais em que vive (Silva, \& Capelle, 2013).

O conhecimento, de acordo com as pressuposições da epistemologia qualitativa, fundamenta-se em três princípios: 1) construtivo-interpretativo, o conhecimento está em contínua produção; 2) compreensão do singular como fonte de produção do conhecimento, que permite considerar a pesquisa como uma produção teórica; e 3) a compreensão da pesquisa como um processo de comunicação e de diálogo. Neste último princípio, parte-se do pressuposto de que os problemas sociais e humanos têm raízes na comunicação entre as pessoas e devem ser compreendidos como um espaço privilegiado para o estudo da subjetividade (González Rey, 2005; Silveira, \& Palassi, 2011). 
Caracterizaram-se como sujeitos desta pesquisa quatro trabalhadores de uma empresa familiar no ramo de cachaçaria que são apresentados na Figura 1. Essa escolha é considerada adequada uma vez que não foi preocupação desta pesquisa a seleção de uma quantidade representativa para compor o quadro de sujeitos investigados, assim como recomendam Godoi e Mattos (2006).

Os entrevistados foram denominados por $\mathrm{E}$ seguido do número da entrevista. A organização foi denominada de modo fictício por "Golo do Sabor". Para proteger a identidade da empresa e dos entrevistados, optou-se por não revelar nenhuma informação que possibilitasse a identificação da organização e dos sujeitos investigados.

\begin{tabular}{|c|c|l|c|}
\hline Entrevistado & $\begin{array}{c}\text { Pertence ao grupo } \\
\text { familiar proprietário } \\
\text { da organização? }\end{array}$ & Especificidades de atuação & $\begin{array}{c}\text { Tempo de } \\
\text { trabalho na } \\
\text { organização }\end{array}$ \\
\hline $\begin{array}{c}\text { Entrevistado 1 } \\
\text { (E1) }\end{array}$ & Sim & $\begin{array}{l}\text { É um dos proprietários da } \\
\text { organização e acumula a função } \\
\text { de diretor executivo da } \\
\text { organização }\end{array}$ & 37 anos \\
\hline $\begin{array}{c}\text { Entrevistado 2 } \\
\text { (E2) }\end{array}$ & Não & $\begin{array}{l}\text { Responsável pelas decisões } \\
\text { financeiras e contábeis }\end{array}$ & 22 anos \\
\hline $\begin{array}{c}\text { Entrevistado 3 } \\
\text { (E3) }\end{array}$ & Não & $\begin{array}{l}\text { Responsável pela estocagem de } \\
\text { materiais }\end{array}$ & 11 anos \\
\hline $\begin{array}{c}\text { Entrevistado 4 } \\
\text { (E4) }\end{array}$ & $\begin{array}{l}\text { Responsável pelas vendas e } \\
\text { disposição dos produtos na loja }\end{array}$ & 1 semana \\
\hline
\end{tabular}

Figura 1. Especificação dos sujeitos da pesquisa

Fonte: Os autores (2017)

González Rey (2005) recomenda ao pesquisador, na fase de coleta de dados, que estabeleça um cenário que permita a ele familiarizar-se com os participantes. Por esse motivo, antes da abordagem direta a qualquer um dos sujeitos, foi feita uma visita ao local e estabelecidas conversações informais com cada indivíduo. $\mathrm{Na}$ sequência, foram agendadas entrevistas individuais em profundidade com os sujeitos da pesquisa, seguindo as recomendações de González Rey (2005) e de Godoi e Mattos (2006).

Vale lembrar que a utilização da entrevista em profundidade é um instrumento de coleta adequado quando o objeto de investigação é constituído por meio de "experiências, ideias, valores e estrutura simbólica" (Godoi, \& Mattos, 2006 p. 305), como no caso desta pesquisa. A entrevista foi guiada por um roteiro com perguntas abertas em que se buscou a compreensão das trajetórias de vida dos 
investigados. Cada entrevista durou em média 60 minutos. Esse tipo de entrevista permite ao entrevistador ter flexibilidade para ordenar e formular as perguntas durante a própria entrevista (Godoi, \& Mattos, 2006).

Os momentos empíricos foram gravados e transcritos na íntegra e de maneira manual. Para a análise das informações coletadas, seguiram-se as recomendações de González Rey (2003; 2005) também tendo-se em vista os procedimentos metodológicos aplicados por Silveira e Palassi (2011). Portanto, não houve um processo de orientação por uma lógica preconcebida, mas foi construído um modelo teórico ao longo do desenvolvimento da própria pesquisa. Nesse processo, buscou-se acessar elementos de sentido que puderam ser transformados em indicativos de sentidos subjetivos.

Os momentos empíricos foram analisados pela técnica de Análise de Conteúdo de Bardin tendo-se em vista a técnica qualitativa que possibilitou a interpretação das informações (Godoy, 1995). Para a definição de categorias, considerou-se o modelo aberto em que as categorias não foram fixas no início, mas tomaram forma no decorrer da análise (Silva, Gobbi, \& Simão, 2005).

\section{DISCUSSÃO DOS RESULTADOS}

Nas três seções deste capítulo, são apresentados os resultados obtidos na pesquisa. Consta-se, na primeira seção, a história da organização, em seguida, apresenta-se as trajetórias de vida dos entrevistados e, por fim, os sentidos subjetivos de trabalho como extensão da vida do fundador.

\subsection{História da Organização: o Lugar, o Produto e o Fundador}

Como os sentidos são compostos pela subjetividade construída socialmente e historicamente (González Rey, 2003), é preciso apresentar a história da organização estudada. A cachaçaria possuía, na data de realização desta pesquisa, produtos para a revenda em todo o território nacional. A organização começou sua produção há mais de três décadas. A sua propriedade é de natureza familiar e foi fundada por Inácio, com apoio dos filhos e da família. Além disso, cabe ressaltar que o fundador é proprietário de um sítio em uma cidade do interior e durante toda a sua vida trabalhou no campo, prioritariamente com o cultivo do café. 
A comercialização da bebida foi aumentando e sendo cada vez mais demandada pela população da região. Um dos filhos fez a primeira logomarca do produto e os demais eram responsáveis pelo engarrafamento da cachaça, que aos poucos foi ganhando identidade, marca profissionalizada e nacionalmente reconhecida. Há aproximadamente dez anos, outro evento que marcou a história da cachaçaria foi o falecimento do fundador. A organização continuou a se desenvolver depois disso. Entretanto, Inácio ainda é constantemente rememorado em todos os principais momentos da cachaçaria.

Em outras palavras, a empresa iniciou por acaso com pequenas produções de cachaça e, gradativamente, foi aumentando sua produção, comercialização e também passou a desenvolver práticas de gestão alinhadas às novas exigências mercadológicas e dos órgãos normatizadores, como Ministério da Agricultura, Pecuária e Abastecimento (MAPA) e Instituto Nacional de Metrologia, Qualidade e Tecnologia (INMETRO). Apesar da profissionalização, conquistada para a adequação às normatizações do contexto, as características de empresa e gestão familiar sempre foram mantidas. E1 explicou que a organização apresenta características diferentes de outros tipos de organização. Tal observação pode ser interpretada a partir da análise do seguinte relato:

[...] A nossa história se confunde com a história do produto. Tem horas que nós não sabemos se nós somos o produto, se nós somos família, isso leva a nossa alma, tem um zelo, um carinho, um amor... Aí percebo uma indústria onde' que não é familiar... Ela tem outro aspecto... Eu não sei falar pra vocês... Eu sei sentir, mas não sei explicar [...]

E1 evidencia que a história da organização confunde-se com a história de vida dos sujeitos que lá trabalham. Essa relação justifica-se uma vez que, além dos filhos, alguns trabalhadores desenvolveram suas subjetividades e histórias de vida juntamente com a história da organização. Apesar de também contar com trabalhadores que não vivenciaram todas as etapas históricas da empresa e com indivíduos que não pertencem ao grupo familiar organizacional, E1 interpreta a empresa como "uma família". Como características destacadas pelo entrevistado que diferenciam a organização familiar, são citados: "o zelo, o carinho e o amor".

O fato de o entrevistado não saber diferenciar "o que é o produto e o que é a família" pode ser justificado por esse indivíduo ter desenvolvido sua socialização primária juntamente com a história da "Golo do Sabor", fato que, de acordo com 
Berger e Luckmann (2004), influencia na maneira como os sujeitos percebem e interiorizam a realidade. Carrieri e Lopes (2012) também fizeram essa observação no caso que pesquisaram.

$A$ emoção de E1 é percebida quando ele afirma que, em relação às diferenças a outros tipos organizacionais, a "Golo do Sabor" tem um aspecto que ele sabe "sentir", mas não "sabe explicar". González Rey (2003; 2007) compreende que a emoção, o sentimento e a percepção do sujeito estão estreitamente relacionados aos seus sentidos subjetivos que, neste caso, relacionam-se às relações afetivas e emocionais ligadas diretamente à organização familiar em questão.

Esses sentidos subjetivos foram ainda mais evidenciados nas categorias de análise que apresentam as trajetórias de vida dos entrevistados e, principalmente, na categoria que trata da percepção do trabalho como extensão da vida do fundador.

\subsection{Os Entrevistados: Conhecendo as Trajetórias de Vida}

A subjetividade de um indivíduo é algo complexo e recebe diversas influências. A realidade do homem, o sentido que atribui a essa realidade depende de suas necessidades, ideologias, aspirações e desenvolvimento histórico, sobretudo, de sua existência única e irrepetível (González Rey, 2003). Assim, é importante conhecer as trajetórias de vida dos quatro entrevistados desta pesquisa (E1, E2, E3 e E4).

O primeiro entrevistado (E1) possui 52 anos, é o filho mais velho do Sr. Inácio e trabalha como diretor executivo da organização juntamente com os irmãos. É casado e possui filhos. Esse gestor afirma que a sua principal característica é ser muito parecido com o pai, principalmente no que refere ao estilo gerencial e emocional. Tanto que considera ser o filho com maior afinidade de pensamento com o Sr. Inácio. O entrevistado demonstrou ser uma pessoa que gosta muito de seu trabalho e ainda é visto pelos funcionários da organização como uma referência, como uma pessoa que gera motivação nos demais.

E2 possui 46 anos, é solteiro e não possui filhos, reside com seus pais na mesma cidade em que está localizada a "Golo do Sabor". O entrevistado possui ensino superior completo com formação em Ciências Contábeis, trabalha com a família de Inácio desde a sua infância. Sua mãe também trabalhou para Inácio 
quando ele comercializava café. Naquela época, E2 ainda era criança. Este entrevistado afirmou que se sente parte da família, que não tem pretensão de sair da organização e que está plenamente realizado lá. O trabalhador interpreta a relação estabelecida com a organização e com a família de Inácio de forma diferente da relação meramente contratual entre patrão e empregado. Ele compreende o trabalho como continuidade de sua vida pessoal e familiar.

E3 possui 33 anos, é solteiro e não possui filhos, entretanto, pretende casarse nos próximos dois anos. Possui ensino médio completo e trabalha na cachaçaria há uma década. O entrevistado é natural de uma cidade vizinha e o seu primeiro trabalho com carteira assinada foi na cachaçaria. E3 trabalha hoje no setor de logística da empresa e afirmou que iniciou as suas funções no setor produtivo. Gosta de seu ambiente de trabalho, sobretudo, das relações lá estabelecidas. Afirmou que espera ir trabalhar em outra organização, visto que pretende mudar-se para a capital, cidade onde irá morar quando se casar. É válido ressaltar que, diferentemente de E1 e E2, En3 vivenciou boa parte de sua socialização primária fora da "Golo do Sabor", fato esse que impactou na constituição de seus sentidos subjetivos de trabalho de forma a não se sentir tão emocionalmente ligado à organização.

E4 é recém-contratado, está aprendendo suas funções e trabalha há uma semana na cachaçaria. Tem 30 anos, é solteiro e não possui filhos. Este entrevistado (E4) é graduado em Psicologia e possui pós-graduação. Ele veio de uma família de baixo poder aquisitivo, de mãe doméstica e pai pedreiro. Após se formar, encontrou uma oportunidade de trabalho no Acre e lá permaneceu durante quatro anos. Entretanto, o seu contrato profissional como psicólogo não foi renovado e precisou retornar à sua cidade de origem. Trabalhar na "Golo do Sabor", mesmo não sendo em sua área de formação, é visto por E4 como uma boa oportunidade, tendo-se em vista as poucas opções disponíveis em sua cidade. O entrevistado afirmou estar motivado e demonstrou pretensão de permanecer na organização. De modo diferente dos demais, este entrevistado vivenciou toda a sua socialização primária e parte da secundária, inclusive em termos de profissionalização, fora da organização.

Embora a origem de cada entrevistado seja diferente, foi possível observar que existem pontos em comum na trajetória de cada um a partir do momento em que foram trabalhar na "Golo do Sabor" como, por exemplo, o sentimento subjetivo 
de pertencimento à organização e o sentimento subjetivo de valorização das relações afetivas lá estabelecidas, conforme já apontado por Davel e Colbari (2000) e Lopes et al. (2013), como características próprias das relações de trabalho em organizações familiares.

Essas observações são evidenciadas na seção seguinte, que trata do sentido subjetivo apreendido de trabalho como "extensão da vida do fundador".

\subsection{O Trabalho como Extensão da Vida do Fundador}

Um sentido subjetivo comum aos participantes desta pesquisa foi o trabalho como extensão da vida do fundador. González Rey (2003) explica que, além da subjetividade individual, formada nos espaços sociais constituídos historicamente, as pessoas também possuem a subjetividade social, aquela que aparece em um dado cenário social. Ao entrar na vida social, o indivíduo transforma-se em sujeito e sua integração nesse espaço diferencia-se pelos processos de socialização, bem como pelos "modelos dominantes de subjetividade social". Desse modo, o sujeito individual dá lugar a novos processos, a novas redes de relações sociais e a novos processos de subjetivação social.

Os trabalhadores da "Golo do Sabor", especialmente aqueles que não desenvolveram sua trajetória de vida lá, ao passarem a pertencer ao grupo social da organização, também tiveram seus sentidos de trabalho modificados. Dentre essas mudanças, observou-se um sentido de trabalho compartilhado pelos gestores e filhos do Sr. Inácio, que enxergam o trabalho desempenhado como uma continuidade do trabalho do pai. Todos os trabalhadores internalizaram esse mesmo sentido subjetivo social.

Percebeu-se que o nome do fundador, suas fotos e frases ditas são espalhados por toda a organização em quadros e fotografias, como um modelo dominante que tem auxiliado a socialização naquele ambiente, como explica González Rey (2003). Os gestores disseminam e reforçam os valores introduzidos pelo Sr. Inácio e rememoram seu nome em todos os momentos no cotidiano da organização.

Lopes et al. (2013) enfatizam que o membro da família que funda a empresa familiar exerce grande influência nas relações de trabalho, na cultura e nos valores reforçados na organização. Para os autores, nessas organizações, as relações 
subjetivas são marcadas por fortes laços afetivos, advindos de uma ligação que antecede os negócios. Nas organizações familiares, são mesclados os papéis profissionais, o racional e o familiar, que sempre é carregado de afetividade oriunda de histórias de vida daqueles que estão lá presentes.

E1 participou diretamente de todas as fases de desenvolvimento da organização, portanto, sua subjetividade individual e social foi desenvolvida em um mesmo contexto. O sentido subjetivo de sua vida profissional confundiu-se com o sentido de sua vida pessoal e familiar. O entrevistado percebeu a organização como uma concretização dos sonhos e da realização de seu pai e de sua família. E1 reconhece a organização como uma continuação da relação afetiva que tinha com seu falecido pai. Essa observação pode ser feita no relato: "E eu ainda falo [...] Que meu pai ainda está por aqui [...] Nas pessoas [...]". Entre os momentos mais difíceis vivenciados por E1 na organização, está a morte de seu pai, que foi marcante. O retorno ao trabalho sem a companhia paterna foi lembrado com grande tristeza.

Observa-se que o sentido subjetivo de trabalho para E1 modificou-se após o falecimento do pai. Ele passou a entender que seria o principal responsável pela condução da empresa e pela concretização dos sonhos do pai, como pode ser percebido no seguinte relato de entrevista:

E eu ficava muito apertado [...] Por que pareceria que eu era cobrado [...] por eu parecer com ele [...] Parece que eu tinha aquela sobrecarga [...] Que parecia que eu tinha que dar conta [...] De fazer do mesmo jeito que meu pai fazia [...] Então eu tive que ter muito jogo de cintura pra eu poder vencer todas essas barreiras [...]".

Os trabalhadores, de acordo com o entrevistado, enxergaram nele o papel que antes era conduzido por Sr. Inácio. Esse sentido subjetivo de cobrança ou autocobrança de E1 pode estar relacionado ao fato de o pesquisado sentir-se parecido com o pai e ainda por ser o filho mais velho. Subjetivamente, por ter tais características semelhantes, ele sentiu-se responsável por assumir um papel que não era dele, mas que, a partir da morte do patriarca, obrigatoriamente passou a ser. O mito do fundador é tão forte na organização que o seu sucessor acabou assumindo a carga de trabalho e o emocional para suprir essa ausência tão marcante para todos.

E2, assim como E1, evidenciou em seus relatos que um dos sentidos subjetivos de seu trabalho é a continuidade da vida do fundador. Refere-se ao "Sr. 
Inácio" no tempo verbal presente, apesar de ele já ter falecido há anos. Afirma que "convive" com ele. Assim como E1, E2 relembrou a sua morte como um dos momentos mais difíceis que já viveu na organização e emocionou-se ao rememorar esse evento:

Agora a morte do Sr. Inácio [...] Isso aí foi um baque, isso aí foi difícil (lágrimas) é até difícil de falar [...] foi mesma coisa que perder alguém da família [...] ele era assim sabe [...] não é um patrão que a gente tem um amigo [...] esse doeu viu?!".

E2 desenvolveu sua subjetividade individual e social de uma maneira muito semelhante e em um mesmo contexto que E1. Ele percebe na relação estabelecida com o patrão mais que uma relação profissional, mas uma relação afetiva e que provoca emoções.

González Rey (2003; 2007) explica que as emoções representam estados de ativação psíquica e fisiológica resultantes de complexos registros do organismo perante o social, o psíquico e o fisiológico. Em outras palavras, a emoção está estreitamente associada ao estado subjetivo de um indivíduo. Além da subjetividade expressa pela emoção ao rememorar a morte do falecido fundador e patrão, E2, assim como os demais atores organizacionais, assumiu para si os sonhos do antigo proprietário da organização.

Lopes et al. (2013) apontam que muitas vezes os familiares e funcionários de empresas familiares possuem desejos de seguirem um caminho próprio, diferente daquele indicado pelo criador do negócio. Entretanto, observa-se que na "Golo do Sabor", o desejo dos funcionários se realiza à medida que eles compreendem, por meio de seus sentidos subjetivos conscientes e inconscientes, que os desejos do fundador estariam também sendo realizados.

E3, assim como E2 e E1, possui um de seus sentidos subjetivos de trabalho compreendidos na organização como extensão da vida de Inácio. Contudo, de igual forma, foi perceptível que o sentido de trabalho para E3, depois do falecimento do patrão, sofreu uma modificação. O entrevistado também utiliza o tempo verbal no presente para se referir ao fundador da cachaçaria. Apesar disso, depois que Inácio faleceu, ele, que tinha apenas um patrão, passou a ter mais de um. E3 expressa que a morte de Inácio também trouxe um sentido subjetivo de "dificuldade" relacionado em receber ordens de mais de uma pessoa. Acredita-se que a figura carismática e 
de autoridade do fundador não será ocupada tão cedo por outra pessoa na organização.

E3, ao contrário de E1 e E2, teve sua subjetividade individual em boa parte constituída fora da organização. Isso pode ter influenciado o fato de E3 perceber aspectos que não foram identificados pelos demais entrevistados. Entretanto, E3 reafirma que se tornou outra pessoa depois que iniciou seu trabalho na "Golo do Sabor" e, ainda, que as relações afetivas estabelecidas na organização ajudam-no a superar tais insatisfações. O entrevistado considerava-se uma pessoa tímida e retraída e percebeu que seu trabalho ajudou a superar esses limites.

Assim como E1 e E2, E3 afirmou que muito do que aprendeu foi graças aos ensinamentos de Inácio. Compreende-se, portanto, que E3 estabelece um processo de reflexividade sobre seu trabalho diferente daquele proporcionado por meio dos modelos dominantes de subjetivação social na organização. González Rey (2003) e Ferreira e Nogueira (2013) explicam que essa reflexividade é própria do sujeito e permite que ele seja crítico e não apenas um reprodutor de práticas sociais de seu meio.

Já E4, que estava há apenas uma semana trabalhando na cachaçaria, falou do Sr. Inácio como se tivesse de fato o conhecido. Revelou que ele era uma pessoa "amiga" e "humilde" e que os filhos não deixarão de continuar a história que foi iniciada por ele. González Rey (2003) explica que um sentido não é composto apenas por momentos inconscientes, mas também conscientes e impõem uma racionalidade ao sujeito. Portanto, compreende-se que, mesmo tendo convivido por pouco tempo na cachaçaria e não tendo conhecido o fundador pessoalmente, E4 já relaciona o seu trabalho na "Golo do Sabor" como uma continuidade de um desejo da família e, sobretudo, de Inácio.

Finalmente, compreende-se que a história da organização e, especialmente, a história do fundador dessa organização, tem feito parte de um dos sentidos subjetivos presentes no cotidiano dos atores organizacionais da cachaçaria. Esse sentido tem sido representado de diferentes formas e é influenciado pelas experiências de cada sujeito. Em outras palavras, a vivência dentro e fora da organização foi percebida como importante na construção de sentidos acerca do trabalho na "Golo do Sabor". 


\section{CONSIDERAÇÕES FINAIS}

$\mathrm{Na}$ empresa familiar investigada, foram revelados diferentes sentidos subjetivos que, apesar de estarem ligados às características individuais e cognitivas de cada sujeito, também representaram uma construção coletiva das práticas sociais e históricas desenvolvidas na própria organização.

Compreendeu-se que os sentidos subjetivos foram marcados pelo trabalho como extensão da vida do fundador. Observou-se que a morte do patriarca da família provocou mudanças na interpretação que cada indivíduo teve em relação ao próprio trabalho. Ademais, foi possível entender que os trabalhadores da cachaçaria atribuíram sentidos diferenciados a esse acontecimento que tem, desde então, orientado a gestão na organização.

Em síntese, E1, por ser o filho mais velho e sentir-se parecido com o pai, desenvolveu o sentido subjetivo de autocobrança e sobrecarga em relação a seu trabalho. E2, mesmo não sendo pertencente à família proprietária da cachaçaria, por ter vivenciado grande parte de sua socialização na "Golo do Sabor", desenvolveu uma compreensão do trabalho que extrapolou a relação funcionário e patrão, percebendo a empresa como parte de sua família.

Já E3, que vivenciou parte de seu processo de socialização e subjetivação fora da cachaçaria, revelou sentidos subjetivos após a morte do patriarca não reconhecidos pelos demais trabalhadores. Um exemplo citado foi a dificuldade em não reconhecer de fato quem seria o seu patrão. Quanto à E4, mesmo estando inserido há apenas uma semana na organização, já reproduziu em seus relatos o modelo dominante de subjetivação de trabalho como "extensão da vida do fundador".

Todas essas evidências corroboram os apontamentos já realizados pela literatura sobre subjetividade e sentidos subjetivos em empresas familiares. As relações de trabalho nessas organizações são influenciadas tanto pelas relações da família como pelo "mito do fundador". Assim, a empresa é compreendida como uma extensão da vida familiar e os vínculos estabelecidos entre patrão e empregado são diferentes daqueles próprios de outras tipologias organizacionais. Assim, as relações afetivas e familiares são marcantes nas relações de trabalho em empresas familiares. 
Como limitação do estudo, considera-se que seja a própria natureza da pesquisa que se concentrou na investigação de uma única organização. Este fato não diminui a relevância e abrangência do trabalho de proporcionar a reflexão sobre a teoria analisada, entretanto, também não permite generalizações.

São sugeridas, portanto, pesquisas futuras que apliquem essa teoria em organizações que utilizem lógicas diferentes como, por exemplo, organizações de terceiro setor, ou organizações públicas. Também um estudo multicasos em um mesmo setor pode trazer importantes contribuições para o entendimento dos sentidos subjetivos acerca do trabalho.

\section{REFERÊNCIAS}

Antunes, R. (2005). O caracol e sua concha: ensaios sobre a nova morfologia do trabalho. São Paulo: Boitempo.

Aygören, H., \& Nordqvist, M. (2015). Gender, ethnicity and identity work in the family business. European Journal of International Management, (9) (2), pp. 160-178.

Bauman, Z. (1998). Work, Consumerism and the new poor. Buckingham: Open University Press.

Belmonte, V. A. B., \& Freitas, W. R. S. (2013). Empresas familiares e a profissionalização da gestão: estudos de casos em empresas paulistas. Revista de Administração da UFSM, v. 6(1), pp. 71-90.

Bendassolli, P. F., Coelho-Lima, F., Pinheiro, R. A., \& Siqueira Gê, P. C. (2015). The Brazilian Scientific Production on Sense and Meaning of Work: Review of Use of Terminology and Current Thematic Classifications. Avances en Psicología Latinoamericana, v. 33(2), pp. 203-221.

Berger, P. L., \& Luckmann, T. (2004) A construção social da realidade: tratado de sociologia do conhecimento. Petrópolis: Editora Vozes. 
Carrieri, A. P., \& Lopes, F. T. (2012). "O avô constrói, o pai usa e o neto morre de fome": histórias de família em uma organização. Rege - Revista de Gestão, v. 19(1), pp. 3-20.

Davel, E., \& Colbari, A. (2000). Organizações familiares: por uma introdução a sua tradição, contemporaneidade e multidisciplinaridade. Organização \& Sociedade, v. 7(18), pp. 45-64.

Ferreira, J. M., \& Nogueira, E. S. (2013) Mulheres e Suas Histórias: Razão, Sensibilidade e Subjetividade no Empreendedorismo Feminino. Revista de Administração Contemporânea, v. 17(4), pp. 398-417.

Frezatti, F., Bido, D. S., Mucci, D. M., \& Beck, F. (2017). Estágios do ciclo de vida e perfil de empresas familiares brasileiras. Revista de Administração de Empresas, v. 57(6), pp. 601-619.

Garcia, E. C., \& Moreira, M. O. M. (2008, setembro). "Somos uma grande família": o papel do mito da grande família no controle psicossocial por vínculos. Anais do Encontro da Anpad. Rio de Janeiro, RJ, Brasil, 14.

Godoi, C. K., \& Mattos, P. L. C. L. (2006). Entrevista qualitativa: instrumento de pesquisa e evento dialógico. In: Silva, A. B., Godoi, C. K., \& Bandeira-de-Mello, R. (Orgs). Pesquisa qualitativa em estudos organizacionais: Paradigmas, Estratégias e Métodos. São Paulo, SP: Editora Saraiva.

Godoy, A. S. (1995). Pesquisa qualitativa: tipos fundamentais. Revista de Administração de Empresas, v. 35(3), pp. 20-29.

Gonçalves, J. S. R. C. (2000). As empresas familiares no Brasil. Revista de Administração de Empresas, v. 7(1), pp. 7-12.

González Rey. F. L. (2007) As categorias de sentido, sentido pessoal e sentido subjetivo: sua evolução e diferenciação na teoria histórico-cultural. Psicologia da Educação, v. 24(1), pp. 155-179. 
González Rey. F. L. (2005). Pesquisa qualitativa e subjetividade: os processos de construção da informação. São Paulo, SP: Editora Thomson Learning.

González Rey. F. L. (2003). Sujeito e Subjetividade:uma aproximação históricocultural. São Paulo, SP: Editora Thompson Learning.

Harper, D. (2017). Online Etymology Dictionary. Disponível em: <http://etymonline.com/?search=schala>. Acesso em: 13 jun. 2017.

Junqueira, A. G. W., Medeiros C. R. G., Schwingel, G., Carreno, I., Saldanha, O. M. F., \& Jungles, L. A. P. (2011). Sentido e significado do trabalho para enfermeiros e médicos da estratégia de saúde da família. Estudo \& Debate em Gestão e Planejamento, v. 18(2), pp. 23-35.

Leontiev, A. N. (1992). Ecce Homo. Methodological Problems of the activity theoretical approach. Multidisciplinary newsletter for Activity Theory, v. 11(12), pp. 41-44.

Leontiev, A. N. (1978). Actividad, conciencia y personalidad. Buenos Aires: Edição Ciencias del Hombre.

Lescura, C., Brito, M. J., Borges, A. F., \& Capelle, M. C. A. (2012). Representações Sociais sobre as Relações de Parentesco: Estudo de Caso em um Grupo Empresarial Familiar. Revista de Administração Contemporânea, v. 16(1), pp. 98117.

Lopes, F. T., Carrieri, A., \& Saraiva, L. A. S. (2013). Relações de Poder e Subjetividade em uma Organização Familiar. Organização \&Sociedade, v. 20(65), pp. 225-238.

Lopes, F.T., \& Carrieri, A. P. (2010). Fotografias de família pela ótica das sucessoras: um estudo sobre uma organização familiar. Revista de Administração Contemporânea, v. 14(3), pp. 478-494. 
Lourenço, C. D. S., \& Ferreira, P. A. (2012). Cultura Organizacional e mito fundador: um estudo de caso em uma empresa familiar. Gestão e Regionalidade, v. 28(84), pp. 61-76.

Müller, H. P. (2005). Trabalho, profissão e vocação: o conceito de trabalho em Max Weber. In. Mercure, D., \& Spurk, J. (Orgs). O trabalho na história do pensamento ocidental. Petrópolis, RJ: Editora Vozes.

Schmidt, M. L. G., Barbosa, W. F., Pinceli, S. C. C, \& Lucca, S. R. (2017). Significados e sentidos do trabalho: reflexos para a atuação do médico do trabalho na contemporaneidade. Revista Psicologia, Diversidade e Saúde, v. 7(3), pp. 138-142.

Schweitzer, L., Gonçalves, J., Tolfo, S. R., \& Silva, N. (2016). Bases epistemológicas sobre o sentido(s) e significado(s) do trabalho em estudos nacionais. Revista Psicologia: Organizações e Trabalho, v. 16(1), pp. 103-116.

Short, J. C., Sharma, P., Lumpkin, G. T., \& Pearson, A. W. (2016). Oh, the Places We'll go! Reviewing past, present, and future possibilities in family business research. Family Business Review, v. 29(1), pp. 11-16.

Silva, C. R., Gobbi, B. C., \& Simão, A. A. (2005) O uso da análise de conteúdo como uma ferramenta para a pesquisa qualitativa: descrição e aplicação do método. Organizações Rurais \& Agroindustriais, v. 7(1), pp. 70-81.

Silva, K. A. T. (2013). A luz "vermelha" no fim do túnel: sentidos subjetivos do trabalho na prostituição. Dissertação de Mestrado. Universidade Federal de Lavras, Lavras, MG, Brasil.

Silva, K. A. T. S., \& Cappelle, M. C. A. (2013, novembro). A Teoria da Subjetividade e a Epistemologia Qualitativa de Gonzalez Rey como Possibilidade Teórico-Metodológica nos Estudos de Administração. Anais do IV Encontro de Ensino e Pesquisa em Administração e Contabilidade (Enpq). Brasília, DF, Brasil,13. 
Silveira, R. Z., \& Palassi, M. P. (2011). A vida na fazenda: sentidos subjetivos do servidor fazendário ante a participação no trabalho. Revista de Administração Mackenzie, v. 12(6), pp. 192-223.

Souza, E. O., Maranhão, T. L. G., Leone, N. M. C. P. G., \& Oliveira, G. F. (2017). Cultura organizacional em empresa familiar: uma revisão sistemática. Revista Multidisciplinar e de Psicologia, v. 11(36), pp. 13-37.

Tacca, M. C. V. R., \& González Rey, F. L. (2008). Produção de sentido subjetivo: as singularidades dos alunos no processo de aprender. Psicologia Ciência e Profissão, v. 28(1), pp. 138-161.

Tolfo, S. R., \& Piccinini, V. (2007). Sentidos e significados do trabalho: explorando conceitos, variáveis e estudos empíricos brasileiros. Psicologia e Sociedade, v. 19(1), pp. 38-46.

Vygotsky, L. S. (1987). "Thinking and Speech". The Collected Works of L. S. Vygotsky. Nova York: Plenum Press.

Vygotsky, L. S. (1968). Pensamiento y lenguaje. Buenos Aires:Edição Ciencias del Hombre. 